\title{
ASSESSMENT OF THE AWARENESS AND OPINIONS OF TURKISH MEDICAL STUDENTS TOWARDS VIOLENCE AGAINST WOMEN: A QUESTIONNAIRE-BASED STUDY
}

\author{
Fatih Erkan Akay $^{1}$ (D) Ilgın Kılıç ${ }^{2}$ (D), Nur Gülce İşkan ${ }^{1}$ (D), Begüm Söyleyici ${ }^{1}$ (D), \\ Ece Şenyiğit ${ }^{1}$ (D), Gülsüm Önal ${ }^{3}$ (i)
}

\author{
${ }^{1}$ Trakya University School of Medicine, Edirne, TURKEY \\ ${ }^{2}$ University of Liverpool School of Medicine, Liverpool, ENGLAND \\ ${ }^{3}$ Department of History of Medicine and Medical Ethics, Trakya University School of Medicine, Edirne, TURKEY
}

\begin{abstract}
Aims: This study aims to evaluate the opinions of medical students about violence against women, the education they receive during medical school regarding violence against women, and how they would manage a case of violence victims if they were to encounter it in their medical careers. Methods: In this questionnaire-based study, 610 medical students from 37 medical schools were approached, and their opinions towards violence against women were evaluated through an online questionnaire. Demographic data such as age and gender were also gathered. Students were grouped according to their gender (male and female) and study levels; 1st, 2nd, and 3rd grades were grouped as pre-clinical, whereas students in 4th, 5th, and 6th grades were grouped as clinical. In comparing parametric variables, the Student's t-test was used, whereas, in non-parametric variables, the Mann-Whitney U test was used. The Chi-square test was used in the comparison of categorical variables. Results: There was a statistically significant difference within both groups (gender and study levels) for questions 5 (Which of the following would you describe as violence? [Multiple answers are allowed.]) and 13 (Do you think female physicians are exposed to violence more?). Our results also demonstrate a statistically significant difference for questions 15 (Is it obligatory for a physician to keep a legal report for a female patient who has been admitted to the emergency department as a victim of violence), 16 (It is not obligatory for a physician to keep a legal report for a female patient who has been admitted to the emergency department as a victim of violence without her consent.), and 17 (A physician is not obliged to complete the physical examination or continue the diagnosis-treatment process of a female patient who has been a subject of violence without her consent.) between pre-clinical and clinical groups, where the clinical group gave the most correct answers. Conclusion: In conclusion, our results gave us a perspective that clinical students' awareness and management of violence against women is higher than pre-clinical students'. These results may be attributed to two factors; lectures on violence against women or the experience students attain during their clinical practices. Female students were keener in participating in our study. Further prospective studies with equal gender distribution investigating the possible impact of lectures about violence against women on physicians' management of similar situations are needed. Keywords: Violence, medical students, awareness
\end{abstract}

\section{INTRODUCTION}

Violence against women (VAW) has been an ongoing issue in the world and has been accepted as a form of human rights violation in the last two decades (1). The United Nations defines VAW as an act of "gender-based violence that results in or is likely to result in, physical, sexual, or mental harm or suffering to women, including threats of such acts, coercion or arbitrary deprivation of liberty, whether occurring in public or private life" (2). VAW is the primary cause of female mortality and morbidity, affecting $35 \%$ of women globally (3). VAW is present in every country in the world, and it significantly affects Turkey (1). According to a questionnaire study conducted in Turkey in $2009,42 \%$ of women that are 16 to 60 years old have experienced a form of physical or sexual violence by their partners, most commonly by their husbands (4). Similarly, according to a more recent study conducted by Hacettepe University in 2014 , it was found that four women out of ten in Turkey have been subjected to physical violence by their partners, and nearly half of these victims would classify the physical violence they have received as "severe" (5). The study shows that $44 \%$ of women in Turkey have been subjected to emotional violence/abuse by their partners (5). When asked, $43 \%$ of the female study participants stated that "If a woman does not share the same opinion about something with their partner, she should not argue and stay silent", which shows the effects of physical, sexual, and emotional VAW and how this can affect women's thoughts towards their equality in relationships (5).

With the emergence of the coronavirus disease 2019 (COVID-19) pandemic and most families having to stay at home, VAW has increased significantly (6). Many countries including France and Cyprus have reported a 30\% increase in VAW cases since the beginning of the countries' national lockdowns (6). This increase can go up to $50 \%$ in some countries, like Argentina (6). A study conducted in Turkey shows that VAW has increased by $27.8 \%$ in Turkey since the beginning of the COVID-19 pandemic (7). 
With the increasing cases of VAW and femicides, which is defined by the World Health Organization (WHO) as the murder of a woman, the importance of the treaties that aim to prevent VAW have significantly increased (8). Examples of these treaties are the "Universal Declaration of Human Rights" adopted in 1948, "The Convention on the Elimination of All Forms of Discrimination Against Women" adopted in 1979, "Inter-American Convention on the Prevention, Punishment, and Eradication of Violence against Women" in 1994, and the most recent human rights treaty for the prevention of VAW, "The Council of Europe Convention on preventing and combating VAW and domestic violence", also known as the Istanbul Convention (9). Initially, Turkey was the first country to ratify the treaty on 14 March 2012 (10). In March 2021, the Turkish government announced Turkey's withdrawal from the Istanbul Convention (11).

Medical doctors play a vital role in the management of VAW, as most of the time, they are the first contacts for the victims of violence, and appropriate care and management is expected (12). VAW being recognized in a hospital setting gives rise to the opportunity for femicide prevention and appropriate management with therapeutic or conservative measures (13). However, the recognition of violence in victims can be challenging due to a lack of violence-related training in medical curriculums in medical schools across the globe (14). A study conducted in the United Kingdom shows that only $25 \%$ of medical schools provide teaching on sexual assault in their undergraduate medical curriculum (15). This lack of education in medical schools can cause less sensitive approaches towards gender-based crimes and sexual violence and can affect future doctors' abilities to manage such a situation (15). Thus, this affects the care that VAW victims get in hospital settings (15). Including educational sessions that focus on the key points of care for sexual violence and VAW victims, and addressing any potential myths about VAW may help medical students to better manage these types of patients (16).

The aim of this questionnaire-based study is to evaluate the opinions of medical students about VAW, the education they receive on VAW, and how they would manage a case of a victim of violence if they were to encounter it in their medical careers.

\section{MATERIAL AND METHODS}

This study was approved by the Scientific Research Ethics Committee of Trakya University School of Medicine (Protocol Code: TÜTF-BAEK 2021/167). In this questionnaire-based study, 610 medical students from 37 different medical schools were approached and their opinions towards VAW were evaluated through an online questionnaire using Google Forms in the Turkish language. Demographic data including age, gender, and medical school grades were obtained. Students were grouped according to their gender (male and female) and study levels; 1st, 2nd, and 3rd grades were grouped as pre-clinical whereas students in 4 th, 5th, and 6th grades were grouped as clinical (Table 1). Students could select multiple answers for questions 5, 8, 10, 12, 14, and 20 .

The answers given to the questionnaire were compared using SPSS, version 23.0.0. Numbers, percentages, mean, standard deviation, median, and interquartile range (IQR) were used as descriptive statistics. In question 5, 1 point was given in each selection and a total score was calculated for the analysis. The Shapiro-Wilk test was used to determine whether the data were distributed normally or non-normally. Answers given to questions 5, 6, 9, 11, 15, 16, 17, 18 , and 19 were compared between pre-clinical and clinical groups. Answers given to questions 5 and 13 were compared between genders. Answers given to other questions were given as numbers and percentages. In the comparison of parametric variables, Student's t-test was used whereas, in non-parametric variables, Mann-Whitney $U$ test was used. In the comparison of categorical variables, the Chi-square test was used. P-value of $<0.05$ was considered to be statistically significant. Students were not obliged to answer all the questions; hence some of the results may have varied between each other.

\section{RESULTS}

A total of 610 medical students from 37 medical schools in Turkey participated in this questionnaire-based study. Demographic data comprised of 412 (67.55\%) female, 174 (28.53\%) male, $1(0.16 \%)$ non-binary students with $20(3.27 \%)$ not specifying their gender. The median age was 21 years (range: 17-29). Other demographic data involving grade and its division into clinical and pre-clinical years are summarized in Table 2 .

There was a statistically significant difference within both groups (gender and clinical/pre-clinical) for question 5 "How many of the following would you define as 'violence'?" ( $p<0.001)$ (Table 3 ). The distribution of answers chosen is shown in Figure 1 with 'get beaten' 608 (99.8\%) as the most selected option. There was a statistically significant difference found between male and female students for question 13 'Do you think women healthcare workers are exposed to more violence?' $(\mathrm{p}<0.001)$.

Between the true or false questions regarding the approach towards a patient who is a victim of violence; question 15 'Is it obligatory for a physician to keep a legal report for a female patient who has been admitted to the emergency department as a victim of violence?', question 16 'It is not obligatory for a physician to keep a legal report for a female patient who has been admitted to the emergency department as a victim of violence without her consent,' and question 17 'A physician is not obliged to complete physical examination or continue the diagnosis-treatment process of a female patient who has been a subject of violence without her consent,' were statistically significant between the pre-clinical and clinical groups (Table 4) where clinical students gave the most correct answers. The p-value for questions 15,16 and 17 are $0.018,0.007$, and 0.050 , respectively.

Two-hundred forty-three (98\%) students considered psychological/mental violence as an emergency that should be sought medical help for. Followed sequentially by physical $[n=238$ (96\%)], and sexual violence $[\mathrm{n}=235(94.8 \%)]$, and economic $[\mathrm{n}=65$ $(26.2 \%)]$. and cyberviolence $[n=65(26.2 \%)]$. The most selected answer $[n=549(90.4 \%)]$ for defining the origin of violence was "social gender constructs". Followed sequentially by "neurochemical and psychiatric factors" [n=405 (66.7\%)], "hormonal" [n=128 (21.1\%)] and "genetic factors" $[\mathrm{n}=119(19.6 \%)]$. It should be noted that multiple answers could be selected in these two questions. The distribution of answers for questions 8, 10, and 14 are shown in Figures 2, 3 , and 4 , respectively. 
Table 1: The questionnaire used in the study.

Questions

$1 \quad$ Your age?

2 How would you describe your gender?

$3 \quad$ Name of your medical school.

$4 \quad$ What is your grade?

$5 \quad$ Which of the following would you describe as violence? (Multiple answers are allowed.)

What is the most up-to-date international document on combat-

6 ing violence against women and domestic violence? (Open-ended question)

7 Do you think that there should be lectures on violence against women in the curriculum of medical schools?

8 If your answer to question 7 is 'Yes', please specify the reason. (Multiple answers are allowed.)

9 Do you think the lectures on violence against women in the curriculum of medical schools are sufficient?

10

If your answer to question 9 is 'No', please specify the reason. (Multiple answers are allowed.)

11 Do you think violence is a medical problem?

If your answer to question 11 is 'depends on the type of the vio-

12 lence', which type of violence, victims should seek for help? (Multiple answers are allowed.)

13 Do you think female physicians are exposed to violence more?

What would you do as a doctor if a female patient who has been

14 subjected to violence is admitted to your hospital? (Multiple answers are allowed.)

Is it obligatory for a physician to keep a legal report for a female 15 patient who has been admitted to the emergency department as a victim of violence?

It is not obligatory for a physician to keep a legal report for a

16 female patient who has been admitted to the emergency department as a victim of violence without her consent.

A physician is not obliged to complete the physical examination

17 or continue the diagnosis-treatment process of a female patient who has been a subject of violence without her consent.

If the initiation of the judicial process would cause harm to the patient who has been subjected to violence, the notification may be postponed until the patient's health conditions become appropriate.

19 Do you think physicians play a role in preventing violence against women?

20 How would you describe the origin of violence against women? (Multiple answers are allowed.)
Answers

Male / Female / Do not want to specify / Other

Preparatory year / 1/2/3/4/5/6

To belittle / Demand obedience / Exposure to aggressive behaviors / Jealousy-Suspicion / Force into sexual acts / To punch / To say 'ugly' / To exploit service / Condemn-Criticize / Quick-temperedness

/ Get threatened / Force to take care of the children / Get beaten / Inhibit or hinder economic independence / Verbal abuse / Physical abuse / Confiscate partner's money / Disallow to work

Yes / No

It is a common problem / Violence against women, domestic violence and neglect have a significant effect on health and society / It

is needed for clinicians to be aware of, recognize, understand, and seek help for violence against women, domestic violence, and abuse / It is needed to enable clinicians to provide an appropriate approach and management to women and those affected by domestic violence or abuse

$$
\text { Yes / No }
$$

There is not enough time / It is not seen as a medical problem / It was only recently decided as an important issue to consider and cover in medical school / This issue can be undertaken in other faculties

$$
\text { Yes / No / Depends on the type of violence }
$$

Physical violence / Psychological-emotional violence / Sexual violence / Economic violence / Cyberviolence

\section{Yes / No}

I would notify judicial authorities like prosecutors, law enforcement officers, etc. / I would notify administrative authorities such as the chief physician, local health authorities / I would notify institutions and non-governmental organizations that have violence support lines available / I would call the hospital social services / I do not know what to do

$$
\text { Yes / No }
$$

True / False

True / False

True / False

Yes / No

Genetic factors / Hormonal factors / Neurochemical-psychiatry problems / Social gender constructs 
Table 2: Summary of the demographic data of the participants.

\begin{tabular}{lc} 
& $\boldsymbol{n}(\%)$ \\
\hline Gender & $412(67.55)$ \\
Female & $174(28.53)$ \\
Male & $1(0.16)$ \\
Non-binary & $20(3.27)$ \\
Prefer not to say & $3(0.49)$ \\
Missing data & $21(3)$ \\
Age (years) & \\
Grade & $154(25.24)$ \\
1 & $90(14.75)$ \\
2 & $175(28.68)$ \\
3 & $60(9.88)$ \\
4 & $55(9.0)$ \\
5 & $71(11.64)$ \\
6 & $5(0.81)$ \\
Missing data & \\
Study level & $419(68.7)$ \\
Pre-clinical & $186(30.4)$ \\
Clinical & $5(0.81)$ \\
Missing data & $610(100)$ \\
\hline
\end{tabular}

*Non-parametric values were given as median (IQR).

Table 3: Comparison of answers given by female versus male study groups.

\begin{tabular}{lccc} 
Question Number & Female & Male & P-value \\
\hline $\mathbf{5}^{*}$ & $18(2)$ & $16.50(4)$ & $<\mathbf{0 . 0 0 1}$ \\
$\mathbf{1 3}^{* *}$ & & & $<\mathbf{0 . 0 0 1}$ \\
Yes & $333(80.8)$ & $91(52.3)$ & \\
No & $79(19.2)$ & $82(47.1)$ & \\
Missing data & 0 & $1(0.6)$ & \\
\hline
\end{tabular}

${ }^{*}$ Data is expressed as median (interquartile range).

**Data is expressed as number and percentages.

Statistically significant values are marked in bold.
Table 4: Comparison of the answers given by clinical versus pre-clinical study groups.

\begin{tabular}{|c|c|c|c|}
\hline Question Number & $\begin{array}{c}\text { Pre-clinical } \\
\text { Students' Answers }\end{array}$ & $\begin{array}{c}\text { Clinical Students' } \\
\text { Answers }\end{array}$ & P-value \\
\hline $5^{\star}$ & $17(2)$ & $18(2)$ & 0.004 \\
\hline $6^{* *}$ & & & 0.507 \\
\hline True & $215(51.3)$ & $90(48.4)$ & \\
\hline False & $204(48.7)$ & $96(51.6)$ & \\
\hline $9^{\star \star}$ & & & 0.588 \\
\hline Yes & $394(94)$ & $172(92.5)$ & \\
\hline No & $25(6.0)$ & $14(7.5)$ & \\
\hline $11^{\star *}$ & & & 0.559 \\
\hline Yes & $269(64.2)$ & $127(68.3)$ & \\
\hline No & $16(3.8)$ & $5(2.7)$ & \\
\hline $\begin{array}{l}\text { Depends on the } \\
\text { type of violence }\end{array}$ & $134(32.0)$ & $54(29.0)$ & \\
\hline $15^{\star *}$ & & & 0.018 \\
\hline Yes & $319(83.3)$ & $166(90.7)$ & \\
\hline No & $64(16.7)$ & $17(9.3)$ & \\
\hline $16^{* *}$ & & & 0.007 \\
\hline True & $155(40.4)$ & $51(28.7)$ & \\
\hline False & $229(59.6)$ & $127(71.3)$ & \\
\hline $17^{* *}$ & & & 0.050 \\
\hline True & $260(67.7)$ & $135(75.8)$ & \\
\hline False & $124(32.3)$ & $43(24.2)$ & \\
\hline $18^{\star *}$ & & & 0.067 \\
\hline True & 289 (74.9) & $118(67.4)$ & \\
\hline False & $97(25.1)$ & $57(32.6)$ & \\
\hline $19^{* *}$ & & & 0.417 \\
\hline Yes & $307(75.2)$ & $129(72.1)$ & \\
\hline No & $101(24.8)$ & $50(27.9)$ & \\
\hline
\end{tabular}

${ }^{*}$ Data is expressed as median (IQR).

${ }^{*}$ Data is expressed as number and percentages.

Statistically significant values are marked in bold. 


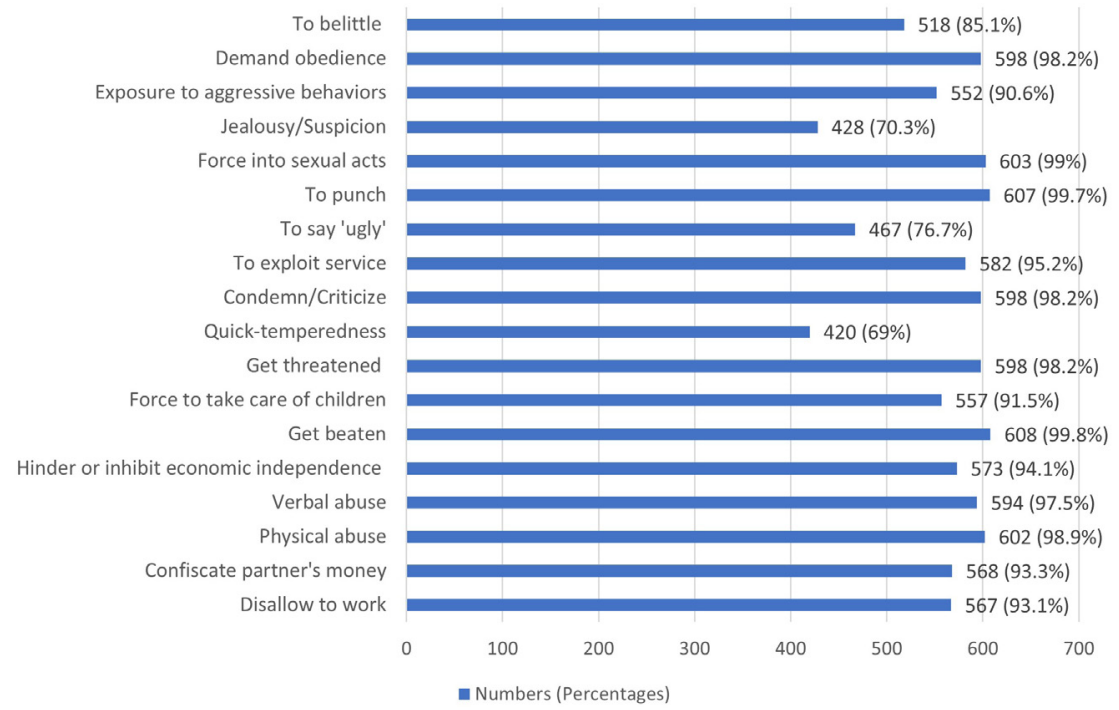

Figure 1: Distribution of answers chosen for question 5 "How many of the following would you define as 'violence'?”.

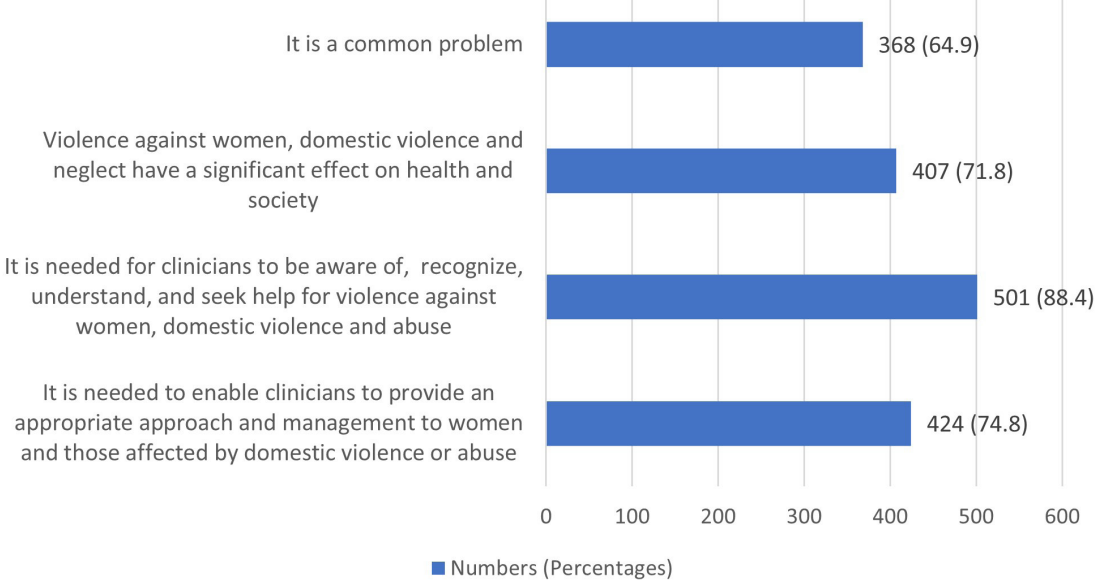

Figure 2: Distribution of answers selected for question 8 "If your answer to question 7 is 'Yes', please specify the reason. (Multiple answers are allowed.)".

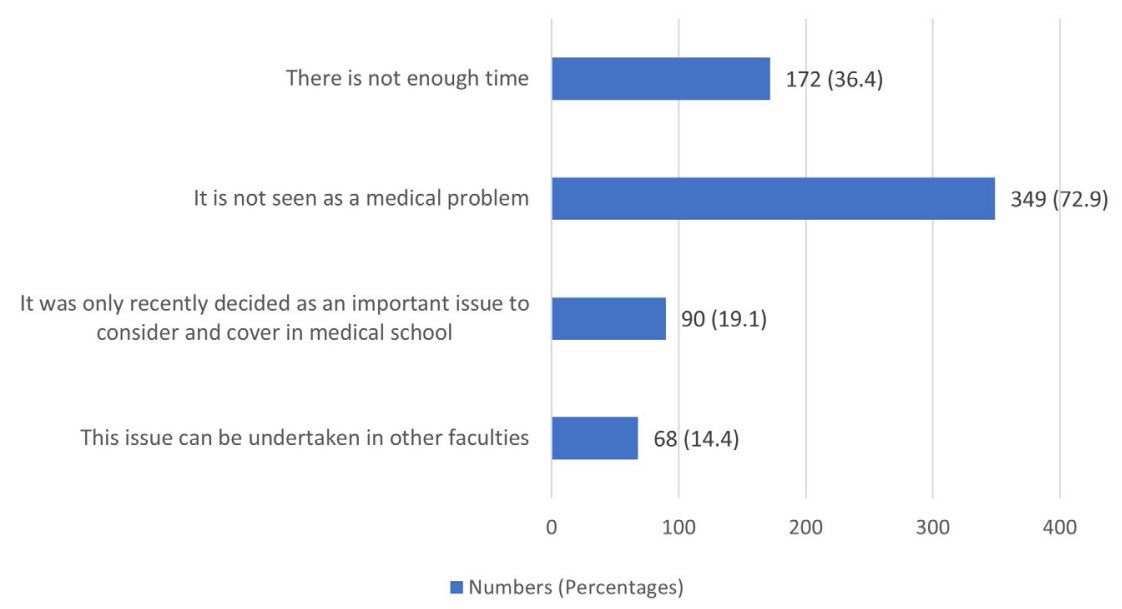

Figure 3: Distribution of answers selected for question 10 "If your answer to question 9 is 'No', please specify the reason. (Multiple answers are allowed.)". 


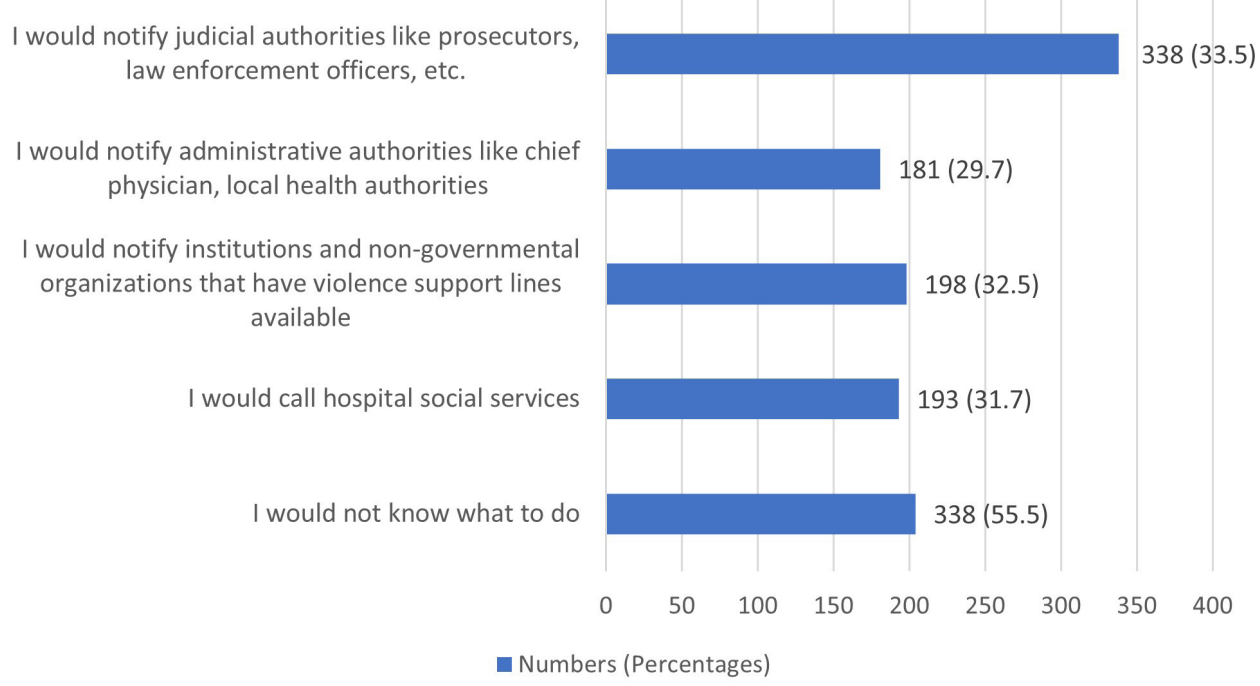

Figure 4: Distribution of answers selected for question 14 "What would you do as a doctor if a female patient who has been subjected to violence is admitted to your hospital? (Multiple answers are allowed.)".

\section{DISCUSSION}

Violence against women is a significant public health problem and a violation of human rights. Estimates published by WHO indicate that about $30 \%$ of women worldwide have been subjected to either physical and/or sexual intimate partner violence or non-partner sexual violence in their lifetime (17). Thus, having sufficient education about VAW in the medical school undergraduate curriculum plays a cardinal role in medical students to recognize and manage victims of violence (18). Therefore, our study aimed to evaluate the attitude of medical students towards VAW and the education they receive on it, and how they would manage VAW cases.

In a study conducted by Ernst et al. (18), students were given a general-knowledge survey about VAW before and one month after 3 hours lecture about VAW. They demonstrated a statistically significant difference between male and female students, indicating a lack of knowledge about VAW in the male student population. In this manner, our study also resulted in a statistically significant difference between male and female students when asked to define violence. However, since female students [412 (67.7\%)] constituted most of our study population, it could have rendered a biased nature in our results. Two other studies, with equal distribution of male and female participants, similarly showed a less sensitive approach in male student groups towards rape victims $(19,20)$. William et al.s (19) questionnaire-based study about rape myths revealed how male students were more likely to accept such myths. In our study, 603 (99\%) of students defined "forcing into sexual acts" as a type of violence, exhibiting an overall awareness concerning this topic.

Looking at question 5 from a different perspective, there was a statistically significant difference found between pre-clinical and clinical students, in which clinical students had a higher score in defining violence, indicating that lectures throughout clinical curriculums increase awareness towards VAW. Similarly, Kennedy et al. (16) and Ernst et al. (18) have shown that courses about violence significantly improve the survey results of medical students. This is especially important for future doctors who will embark on their careers. In this regard, when the students were asked whether they think lectures on VAW should be included in their curriculum, 568 (93.3\%) of the participants answered, "Yes" with the most agreeable reason being "It is needed for clinicians to be aware of, recognize, understand, and seek help for violence against women, domestic violence, and abuse" [ $\mathrm{n}=510(88.4 \%)]$. According to the study conducted by Potter et al. (21), nearly $90 \%$ of medical students have stated that providing a formal education about VAW should be mandatory in medical schools. In the mentioned study, the most selected answer for the question "Why do you think there should be formal teaching on domestic violence and abuse in the curriculum?" was "Violence against women is a common, hidden, and important problem."

A study conducted by Manuel et al. (14) indicates that the undergraduate curriculums in medical schools focus more on diseases and treatments rather than managing potential complex effects of some conditions, including psychological manifestations. In a similar study, Çalıkoglu et al. (22) reported that less than half of their participants [173 (48.5\%)] felt competent in recognizing and managing VAW victims. Likewise, our study shows how 204 (33.4\%) participants felt unsure and did not know how to manage a situation where they would encounter a female patient who was a VAW subject. Following the questionnaire, 500 (83.6\%) students believe that the available courses in their medical school curriculum on VAW are insufficient, expressing their reasoning by selecting the answer "It is not seen as a medical problem" the most [349 (73.9\%)]. Although 398 (65.4\%) participants consider VAW a medical problem, WHO reports VAW as a universal issue, an entity that needs to be grasped and taught more in medical schools (10).

Even though there was a statistically significant difference demonstrated in male $[\mathrm{n}=91(56.9 \%)]$ and female $[\mathrm{n}=333(80.8 \%)]$ students for question 13 "Do you think female physicians are exposed to violence more?", it has been reported that male physicians are subjects of physical $[n=65(45.8 \%)]$ and verbal $[n=132(93 \%)]$ violence more than female physicians (23). However, Demirci et al.'s (24) results demonstrated how female physicians are more prone to verbal/sexual violence. Our results indicate how female medical students are more concerned about working in the field as future doctors.

When asked whether physicians play a role in preventing VAW, 438 (74.2\%) students answered, yes. Further questioning their actions in a possible situation, $487(85.6 \%)$ students stated that they 
would report the given situation to legal authorities. The reason why a high percentage of students selected these answers might be to evade potential legal consequences that they might face. However, this might contradict the "non-maleficence" principle of medicine since the victim's safety should come first and legal action might sometimes result in harm rather than a benefit. Moreover, the answer given for question 14 demonstrates a perception of healthcare workers playing an active role in preventing VAW. This demeanor may also lead to averting femicides after all, which is the greatest endpoint violence can get.

Case-based management of students based on their study levels was evaluated in our study. There was a statistical significance found for questions 15,16 , and 17, where students in the clinical group showed a higher percentage in answering the questions correctly. These results provide that having taken lectures on VAW; medical students attain a broader perspective in managing similar cases. In a study done in Ireland, Kennedy et al. (16) evaluated attitudes of medical students towards victims of sexual violence. They found that the educational curriculum significantly increases undergraduate medical students' awareness when it comes to issues involving patient care (16).

Taking a closer look at answers given for question 20, it is evident that there still lies a major misconception defining the origin of violence. Despite 549 (90.4\%) students selecting the option for the cause of violence as "social gender constructs", 405 (66.7\%) students picked the answer "neurochemical/psychiatric problems" as a factor for violent behavior as well, representing a misunderstanding which leads to the justification of problems that are not related with VAW. 128 (21.1\%) students have also chosen the answer "hormonal factors" while 119 (19.6\%) students chose "genetic factors" to define the origin of violence. In addition to theoretical views revealing violence as a learned and adaptive behavior, studies have been focusing on trying to uncover its pathophysiological background through a neurochemical and neurophysiological objective (25). The focal point has been the neurochemistry and genetics of serotonin and dopamine. The emergence of aggressive behavior is associated with a faulty gene that controls the production and transportation of serotonin, or defective genes that prohibit serotonin bind to its receptor (25). DNA polymorphisms are found to be closely related to aggressive behaviors. (26). The best-known DNA polymorphism is in the tryptophan hydroxylase (TPH) gene (25). TPH is the enzyme responsible for accelerating serotonin synthesis (26). Low levels of serotonin catabolites were detected in the cerebrospinal fluid of people exhibiting aggressive behavior with different alleles of this gene (26). Furthermore, the incidence of aggressive behaviors in psychiatric patients was found not to be different from "normal" population groups. Nonetheless, it is challenging to elucidate the origin of violence with a single reason since it has a multifactorial background (25).

Our limitation in this questionnaire-based study was the unequal distribution of participants in study groups. Our study population primarily consisted of female students, which could have led to biased answers. Further studies with an increased number of participants and equal distribution of numbers in groups could result in more accurate findings.

In conclusion, our results gave us a perspective that clinical students' awareness and management of VAW is higher than pre-clinical students'. These results may be attributed to two factors; lectures on VAW or the experience students attain during their clinical practices. Yet, many studies show that education may significantly impact students' awareness about VAW. As previously stated, female students were keener on participating in our study. This demonstrates a dichotomy between gender and interest in issues like VAW. Further prospective studies, with equal gender distributions, investigating the possible impact lectures on VAW can have on physicians' management of similar situations are needed.

Ethics Committee Approval: This study was approved by the Scientific Research Ethics Committee of Trakya University School of Medicine (Protocol Code: TÜTF-BAEK 2021/167).

Informed Consent: Informed consent was obtained from participants.

Conflict of Interest: The authors declare no conflict of interest.

Author Contributions: Concept: FEA, IK, NGİ, BS, EŞ, GÖ. Design: FEA, IK, NGİ, BS, EŞ, GÖ. Supervision: GÖ. Resources: FEA, IK, NGİ, BS, EŞ, GÖ. Materials: FEA, IK, NGİ, BS, EŞ, GÖ. Data collection and/or processing: FEA, IK, NGİ, BS, EŞ, GÖ. Analysis and/or Interpretation: FEA, IK, NGİ, BS, GÖ. Literature Search: FEA, IK, NGİ, BS, EŞ, GÖ. Writing Manuscript: FEA, IK, NGİ, BS, EŞ, GÖ. Critical Review: FEA, IK, NGİ, BS, EŞ, GÖ.

Financial Disclosure: The authors declared that this study received no financial support.

Acknowledgements: We would like to thank Burcu Yanık Leblebici, head of the Malatya Education Foundation, and Dr. Berra Doğaner, OSTIM Technical University faculty member, for their contributions in distributing the questionnaire to various medical schools throughout Turkey.

Editor-in-Chief's Note: Two authors of this article, Fatih Erkan Akay and Ilgın Kılıç are members of the editorial board of Turkish Medical Student Journal. However, they did not take place in any stage of the editorial decision of the manuscript. The editors who evaluated this manuscript are from other institutions.

\section{REFERENCES}

1. European Union Agency for Fundamental Rights. Violence against women: an EU-wide survey: main results report. Luxembourg: Publications Office of the European Union; 2014.

2. United Nations. Declaration on the elimination of violence against women. New York: UN; 1993.

3. World Health Organization. Global and regional estimates of violence against women: prevalence and health effects of intimate partner violence and non-partner sexual violence. Geneva: WHO; 2013.

4. Altınay AG, Arat Y. Violence against women in Turkey: a nationwide survey. Istanbul: Punto; 2009.

5. Kaptanoglu Y, Cavlin I, Ergocmen AA et al. Research on domestic violence against women in Turkey. Main Report. Hacettepe University, Institute of Population Studies: 2015.

6. Sharma P, Jamwal D, Mehta A et al. COVID 19- endangering women's mental and reproductive health. JK Science 2020;22(3):106-9.

7. Adibelli D, Sümen A, Teskereci G. Domestic violence against women during the Covid-19 pandemic: Turkey sample. Health Care Women Int 2021;42(3):335-350.

8. World Health Organization. Femicide (serial online) 2012 (cited 2021 Apr). Available from: URL:https://apps.who.int/iris/bitstream/handle/10665/77421/ WHO_RHR_12.38_eng.pdf.

9. United Nations. Multilateral treaties deposited with the Secretary-General. (serial online) (cited 2021 Apr). Available from: URL:https://treaties.un.org/pages/participationstatus.aspx?clang=_en.

10. Gunes A. Legal implications of Turkey's accessions to the Istanbul Convention by enacting and refining its laws on violence against women. Women \& Criminal Justice 2019;31:(3)210-24.

11. Presidential Decision. Official Gazette of the Republic of Turkey (serial online) 2021 Mar 20: 31429. Available from: URL:https://www.resmigazete.gov.tr/eskiler/2021/03/20210320-49.pdf.

12. Ramsay J, Rutterford C, Gregory A et al. Domestic violence: knowledge, attitudes, and clinical practice of selected UK primary healthcare clinicians. Br J Gen Pract 2012;62:647-55.

13. Salaçin S. Sağlık çalıșanlarının kadına yönelik șiddetin önlenmesinde üstlenebilecekleri roller. Toplumsal Cinsiyet, Sağllk ve Kadın (serial online) 2003: (7 screens). Available from: URL:http://www.huksam.hacettepe.edu.tr/Turkce/SayfaDosya/saglik_calisanlarinin_kadina_yonelik.pdf.

14. Manuel B, Roelens K, Tiago A et al. Medical curricula on intimate partner violence in Mozambique. Acta Med Port 2020;33(1):22-30.

15. Koschorke A, Tilzey A, Welch J. Should medical students be taught about rape? A survey of UK medical schools. BJOG 2007;114(2):224-5.

16. Kennedy KM, Vellinga A, Bonner $\mathrm{N}$ et al. How teaching on the care of the victim of sexual violence alters undergraduate medical students' awareness of the key issues involved in patient care and their attitudes to such patients. J Forensic Leg Med 2013;20(6):582-7. 
17. World Health Organization. Violence against women. (serial online) (cited 2021 Apr). Available from: URL:https://www.who.int/news-room/fact-sheets/detail/ violence-against-women.

18. Ernst AA, Houry D, Nick TG et al. Domestic violence: incidence and awareness in a first-year medical school class. Acad Emerg Med 1998;5(1):64-8.

19. Williams L, Forster G, Petrak J. Rape attitudes amongst British medical students. Med Educ 1999;33(1):24-7.

20. Anderson I, Quinn A. Gender differences in medical students' attitudes towards male and female rape victims. Psychol Health Med 2009;14(1):105-10.

21. Potter LC, Feder G. Domestic violence teaching in UK medical schools: a cross-sectional study. Clin Teach 2018;15(5):382-6.

22. Calıkoglu EO, Aras A, Hamza M et al. Sexism, attitudes, and behaviors towards violence against women in medical emergency services workers in Erzurum, Turkey. Glob Health Action 2018;11(1):1524541.
23. Hamzaoglu N, Türk B. Prevalence of physical and verbal violence against health care workers in Turkey. Int J Health Serv 2019;49(4):844-61.

24. Demirci S, Uğurluoğlu Ö. An evaluation of verbal, physical, and sexual violence against healthcare workers in Ankara, Turkey. J Forensic Nurs 2020;16(4):33-41.

25. Glenn AL, Raine A. The neurobiology of psychopathy. Psychiatr Clin N Am 2008;31:463-75.

26. Nielsen DA, Goldman D, Virkkunen M et al. Suicidality and 5-hydroxyindoleacetic acid concentration associated with a tryptophan polymorphism. Arch Gen Psychiatry 1994;51(1):34-8. 